Research Article

\title{
Experimental Study of the Basic Mechanical Properties of Directionally Distributed Steel Fibre-Reinforced Concrete
}

\author{
Fang-Yuan Li (D), Cheng-Yuan Cao, Yun-Xuan Cui, and Pei-Feng Wu \\ Department of Bridge Engineering, College of Civil Engineering, Tongji University, Shanghai 200092, China \\ Correspondence should be addressed to Fang-Yuan Li; fyli@tongji.edu.cn
}

Received 6 April 2018; Accepted 22 May 2018; Published 20 June 2018

Academic Editor: Enzo Martinelli

Copyright (C) 2018 Fang-Yuan Li et al. This is an open access article distributed under the Creative Commons Attribution License, which permits unrestricted use, distribution, and reproduction in any medium, provided the original work is properly cited.

\begin{abstract}
Directionally distributed steel fibre-reinforced concrete (SFRC) cannot be widely applied due to the limitations of current construction technology, which hinders research on its mechanical properties. With the development of new construction technologies, such as self-compacting concrete or 3D printing, directionally distributed SFRC has found new developmental opportunities. This study tested, compared, and analysed the basic mechanical properties of ordinary concrete, randomly distributed SFRC, and directionally distributed SFRC. The differences between the damage patterns parallel and perpendicular to the direction of the steel fibres were evaluated in directionally distributed SFRC. When the fibre volume fraction is high and the compression is applied perpendicular to the fibre direction, as the loading increases, the transverse deformation of the specimen is constrained by the fibres. When the compression is applied parallel to the fibre direction, the fibre cannot effectively constrain the transverse deformation of the specimens. When the volume fraction of directionally distributed steel fibres was $1.6 \%$, the elastic modulus of the directionally distributed steel fibres was $39 \%$ higher than that of ordinary concrete. Comparison of the experimental values of the elastic modulus with those estimated by existing calculation methods revealed that a modification of the current calculation theories may be required to calculate the changes in the elastic modulus of directionally distributed SFRC with a high volume fraction of steel fibres.
\end{abstract}

\section{Introduction}

Steel fibre-reinforced concrete (SFRC) was first introduced in the early 20th century. From 1907 to 1908, Некрасоъ, an expert from the former Soviet Union, incorporated metal fibres into concrete, thus heralding the development of SFRC [1]. The earliest study on SFRC was published in 1910; in the United States, Porter envisaged the incorporation of short steel fibres into the concrete matrix to reinforce the concrete materials. In 1911, Graham proposed the incorporation of steel fibres into ordinary reinforced concrete to improve its strength and volume stability.

In the 1940s, scholars and engineers in the United States, Britain, France, Germany, and other countries applied for and were awarded a series of patents on methodologies of improving the performance of concrete by incorporating steel fibres, enhancing the manufacturing process of steel fibres and improving the shape of steel fibres to enhance the bonding strength with the concrete matrix. In 1963, a series of papers on strength-enhancing mechanism of steel fibres were published by Romualdi and Batson [2, 3]. Since then, research and applications of SFRC have developed rapidly. Scholars and engineers in Europe and the United States applied for and were awarded numerous patents on SFRC. Scholars also published many research papers that better clarified the fibres' reinforcement mechanism in concrete. After the 1970s, the United States developed a melt pumping technology to manufacture low-cost steel fibres, which made practical applications of SFRC feasible. Over the next 20 years, the application of steel fibres has drawn widespread attention.

In China, research on and application of SFRC began in the 1970s, and this work was led by the Commission for Science, Technology and Industry for National Defense and the China Building Materials Academy. Dalian University of Technology of China first derived a formula to calculate the tensile strength of randomly distributed SFRC based on fracture mechanics theory. The results were consistent with 
those given by the theory of composite materials. Zhao's team analysed the reinforcement mechanism and failure pattern of SFRC and systematically conducted theoretical studies of SFRC [4]. Scholars from the former Harbin Institute of Architectural Engineering conducted experimental tests on the basic mechanical properties of SFRC [4]. At the same time, the Committee on Fibre-Reinforced Concrete was set up in the China Civil Engineering Society. The committee compiled and published the "Design and construction procedures of steel fibre-reinforced concrete structure" (CECS 38:93) and the "Test method of steel fibrereinforced concrete" (CECS 13:89). These works laid the foundation for the application and development of SFRC in China. Since 2000, the committee has organized the revision of design and construction procedures and compiled the "Technical specifications for fibre-reinforced concrete structure" (CECS 38:2004) for the Association of Chinese Construction Standardization.

All theoretical assumptions show that the fibres' distribution in different directions in concrete greatly affects its reinforcement efficiency in the concrete matrix $[5,6]$. In the late 1970s, scholars from Italy, Sweden, and other countries announced that by utilizing magnetic devices, the steel fibres' orientation and concentration could be satisfactorily controlled during the vibration processes. These scholars also reported that the bending and shear strengths of directionally distributed SFRC were twice that of randomly distributed SFRC with the same fibre volume fraction. If the fibres were concentrated in a certain position, the enhancement effect could be further improved [6]. However, the original reference could not be found. In addition, the improvements of the compressive and tensile properties were not mentioned.

Before the 21st century, scholars outside China studied several properties of directionally distributed fibrereinforced concrete. However, due to the difficulty of directionally orienting steel fibres, only a few verification tests were conducted to analyse the advantages of directionally distributed fibre concrete compared with ordinary concrete and randomly distributed SFRC. Few in-depth and comprehensive studies were conducted [7-9], and few studies were published outside China on this topic in the 21st century.

The directions of sustained loading applied to most structural components are usually fixed and thus do not change. For example, beam-style components and the bottoms of beams are subjected to sustained tensile stresses for long periods of time. Therefore, under loading in the same direction in randomly distributed SFRC, only the steel fibres aligned with or are at small angles to the loading direction reinforce the components and resist crack propagation. The other embedded steel fibres either do not contribute or do not fully contribute to the reinforcement of the concrete components. This results in wasted steel fibres [10-14]. Placing directionally oriented steel fibres in the predicted direction of tensile stress to control their angular distribution in the concrete would achieve a "precise design" and "flexible design" for the materials. In this way, the reinforcement of the components' strength and toughness by the fibres can be fully utilized, while the fibre fraction can be reduced. This procedure would decrease the construction cost while simultaneously increasing the steel fibres' utilization efficiency to $100 \%$. If this goal is achieved, the application of SFRC will have significant advantages in practical engineering. Related studies have also shown that if the fibres' reinforcement effect in unidirectional fibrereinforced concrete is 1 , the reinforcement efficiency of the bidirectional fibre- (such as steel wire mesh-) reinforced concrete is only approximately 0.4 to 0.5 . The reinforcement effect in three-directional randomly distributed concrete is even lower $[6,12]$.

In this paper, ordinary concrete with the same mixtures was used as a reference, and a comparative test of ordinary randomly distributed SFRC and directionally distributed SFRC was conducted. These tests yielded quantitative property information and laid a foundation for future studies of directionally distributed SFRC. The results of this paper are expected to provide technical support for developing seamless widening and splicing technology for bridges, installing expansion joints in bridges, reducing beam end expansion joints and mitigating cracking of the bridge structure. When randomly oriented steel fibres are included in a bridge's nonstructural components, where cracks are not a concern, and directionally oriented steel fibres are included in the bridge's structural components, where cracks tend to occur, the issue of cracking that has long-puzzled engineers and operators will be mitigated, and the bridge's durability will be greatly improved. The results will also provide support for the application of self-compacting or 3D concrete printing technology based on directionally distributed SFRC.

\section{Preparation of Directionally Distributed SFRC}

Currently, most studies on directionally distributed SFRC focus on directionally orienting steel fibres utilizing a magnetic field. The testing requires particularly complex and expensive magnetic field generating equipment that is difficult to operate. In this paper, directionally distributed SFRC cubic specimens were cast by manually placing the steel fibres layer by layer. During the casting process, the uniformity and directional accuracy were carefully monitored at all times, and the deviations between the test pieces were strictly controlled. The specimen casting operation was relatively simple and easy to control.

2.1. Test Materials. For the tests, a concrete mixture was designed based on GB/T 50080-2016 "Standard for Test Methods of Performance of Ordinary Concrete Mixtures" [15] and JGJ 55-2011 "Specification for mix proportion design of ordinary concrete" [16]. The appropriate materials were selected, and a concrete mixture ratio that met the testing requirements was employed.

(1) Cement: ordinary Portland cement of Hailuo brand P.O42.5 (low alkali).

(2) Fine aggregate: ordinary river sand. It was zone III fine sand with a fineness modulus of 1.73. 
TABLE 1: Mixing ratio of benchmark concrete.

\begin{tabular}{lcccccc}
\hline Cement & Water & Sand & Coarse aggregates & Water reducer SH-II & C $\left(\mathrm{kg} / \mathrm{m}^{3}\right)$ & Slump $(\mathrm{mm})$ \\
\hline 1.0 & 0.40 & 0.92 & 2.04 & 0.0027 & 550 & 48 \\
\hline
\end{tabular}

(3) Coarse aggregate: ordinary gravel with sizes of 5$20 \mathrm{~mm}$ and a continuous grain size distribution. The grades met the requirements.

(4) Additive: SH-II-type naphthalene high-efficiency water reducer made by Shanghai Yaoqian Architectural Painting Co., Ltd.

(5) Steel fibre: milling-type fibres made by Shanghai Harex Steel Fibre Technology Co., Ltd. with the following dimensions: a length of $32.0 \pm 2.0 \mathrm{~mm}$, a width of $2.6 \pm 1.2 \mathrm{~mm}$, a thickness of $0.4 \pm 0.05 \mathrm{~mm}$, and a length-diameter ratio of 35-45. These fibres had a tensile strength of $\geq 700 \mathrm{MPa}$.

2.2. Mixing Ratio of Benchmark Concrete. Mixture ratios that met the specified requirements (good viscosity, cohesion, and water retention) were obtained after trial-and-error experimentation. The specific mixture ratios were as follows:

(1) Water-cement ratio: the maximum content of steel fibres in this test was $144 \mathrm{~kg} / \mathrm{m}^{3}$. As the compressive strength of concrete was not obviously improved by the incorporation of the steel fibres, the watercement ratio of the benchmark concrete was determined according to the method in [16].

The test was conducted using grade C50 concrete. The water-cement ratio was determined to be 0.40 .

(2) Water usage: to accommodate the directional placement of the fibres, the concrete should have a large slump to ensure good viscosity and to reduce the vibration casting time. Additionally, the fine aggregates used in the experiment were fine sand, so the water usage per cubic metre of the specimen was increased by $5-10 \mathrm{~kg}$. Therefore, $220 \mathrm{~kg} / \mathrm{m}^{3}$ of water was used in these specimens.

(3) Sand ratio: in this study, the sand ratio of the benchmark concrete specimens was initially determined to be $31 \%$, as per the method in [16].

(4) The amount of coarse and fine aggregates: a mass calculating method was used to determine the appropriate amount of coarse and fine aggregates, which was $2500 \mathrm{~kg} / \mathrm{m}^{3}$.

(5) Water reducer: trial-and-error casting was conducted using the initially determined mixture ratios as discussed above. Using the workability of the concrete as the main index, the amount of the water reducer to be added was determined to be $1.5 \mathrm{~kg} / \mathrm{m}^{3}$.

The mixture ratios can be also seen in Table 1 .

The strength measured after 28 days, that is, the strength of the finally determined mixture, was $49.2 \mathrm{MPa}$, which met the expected requirements (Table 2). The increase in the
TABle 2: Cubic compressive strength with different ages of the benchmark ordinary concrete.

\begin{tabular}{lccc}
\hline Age $(\mathrm{d})$ & 3 & 7 & 28 \\
Average compressive strength $(\mathrm{MPa})$ & 23.6 & 36.4 & 49.2 \\
\hline
\end{tabular}

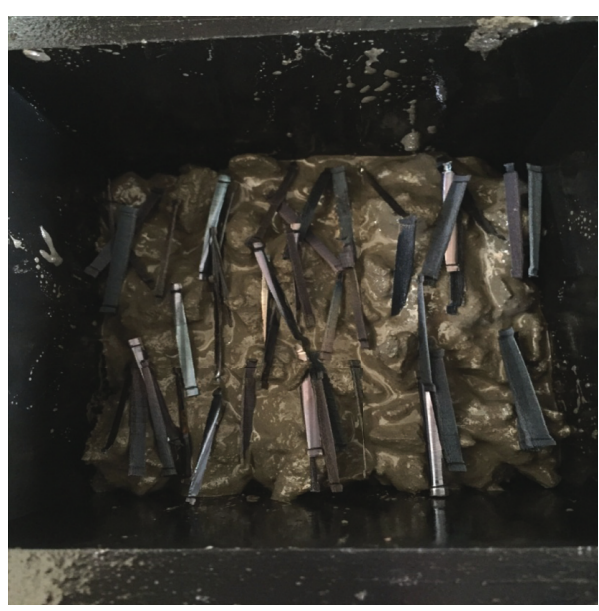

FIgURE 1: Directionally distributed steel fibres in a concrete specimen.

strength of the concrete was rapid at first before gradually slowing in the later period, which agrees with the theoretical predictions.

2.3. Specimen of Directionally Distributed SFRC. Based on the benchmark concrete for normal concrete, the directionally distributed SFRC was made by casting layer by layer and adding directionally oriented steel fibres, as seen in Figure 1.

The cement was evenly mixed with sand, gravel, and water reducer in advance. Then, water was added to the mixture three times until the mixture was completely mixed. The mixture was then poured into an oiled mould layer by layer, each with a height of $20 \mathrm{~mm}$, and each $100 \mathrm{~mm}$ cubic specimen included five uniform layers. The steel fibres for each specimen were weighed and divided equally into four batches. After pouring each layer of concrete, one batch of steel fibres was placed in a particular orientation. The even distribution of the steel fibres across the cross section was confirmed. When adding the steel fibres, the fibre spacing should not be too small with respect to the particle size of the coarse aggregate.

\section{Experimental Study of the Mechanical Properties of Directionally Distributed SFRC Specimens}

Directionally distributed SFRC is a unique composite composed of concrete and unidirectionally embedded steel 


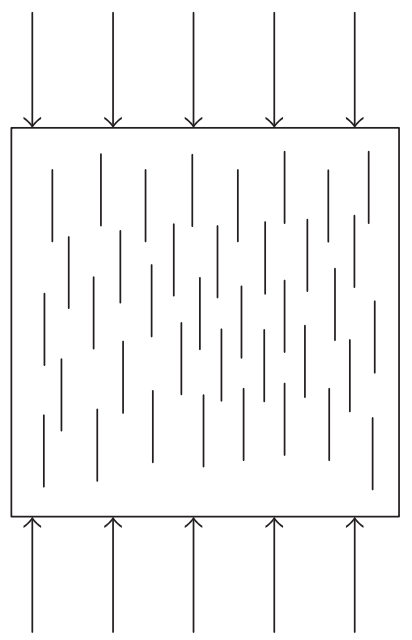

(a)

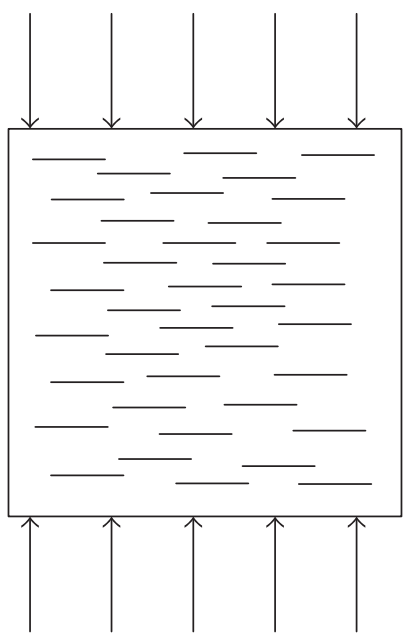

(b)
FIgURE 2: Diagrams of loading directions in the split tensile strength test. Loading applied (a) parallel and (b) perpendicular to the fibre direction.

fibres. Its stress bearing capacity and failure patterns are significantly different from those of ordinary concrete and randomly distributed SFRC [17]. Because of the directional distribution of steel fibres in the concrete, its stress characteristics are anisotropic and more complex than those in ordinary concrete or randomly distributed SFRC, and its test methods and future design and construction methods are unique. Therefore, it is necessary to conduct a comprehensive comparative test of their stress characteristics.

In practical engineering, a concrete structure is rarely subjected to uniaxial loading. However, because the mechanical properties under multiaxial loading are complex, it is difficult to establish a strength theory that can perfectly explain the failure pattern of concrete under different stress conditions. Therefore, most experimental studies are based on the uniaxial strength, which is used to evaluate the basic mechanical properties of concrete structures [18]. In this study, based on relevant research results [19-21] and by using the testing method for ordinary concrete and randomly distributed SFRC, the basic mechanical properties of directionally distributed SFRC were quantitatively studied.

Several types of SFRC specimens were assessed in this study. The concrete's strength grade was C50, and the only variable was the volume fraction of steel ingot-milled fibres. A total of 72 cubic specimens with the dimensions of $100 \mathrm{~mm} \times 100 \mathrm{~mm} \times 100 \mathrm{~mm}$ and seven steel fibre volume fractions were made. The compressive strengths of these 72 specimens were tested. The reinforcement effects of different volume fractions of randomly and directionally distributed steel fibres on ordinary concrete were compared and analysed. The elastic modulus was measured through static compression tests using 30 prism specimens with the dimensions of $100 \mathrm{~mm} \times 100 \mathrm{~mm} \times 300 \mathrm{~mm}$. The influence of different volume fractions of randomly distributed and directionally distributed steel fibres on the elastic modulus of ordinary concrete was compared and analysed. The comprehensive analysis of the basic mechanical properties of steel ingot-milled fibre-reinforced

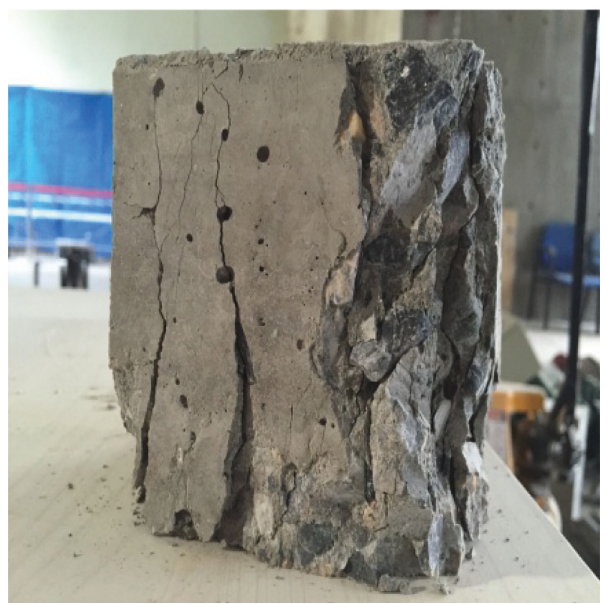

FIGURE 3: Failure pattern of a cubic ordinary concrete specimen under compression.

concrete conducted in this paper provides a theoretical basis and guidance for further study of SFRC and its applications in practical engineering.

The mechanical tests in this paper were carried out in accordance with the provisions in two Chinese national standards: "Standard for test method of mechanical properties on ordinary concrete" GB/T 50081-2002 and "Steel fibre-reinforced concrete" JG/T 472-2015 [15, 22].

3.1. Compressive Strength Test. The compressive strength of ordinary SFRC is not significantly affected by the steel fibre properties and volume fraction. Compared with ordinary concrete, the compressive strength of cubic speciments of SFRC is far less important than its tensile strength, but to coordinate the design of SFRC structures with other design specifications, China's "Specification for design and construction of SFRC structures" [22] stipulates that the strength grade of SFRC should be determined based on the standard cubic compressive strength by following the pertinent specifications for the design of concrete structures. Therefore, the compressive strength of cubic specimens of SFRC is still an important index for evaluating the durability and performance of the concrete matrix.

In this study, compressive tests were conducted with cubic specimens of ordinary concrete, ordinary randomly distributed SFRC, and directionally distributed SFRC with seven different fibre volume fractions. The compressive strength tests of the directionally distributed SFRC were conducted both parallel and perpendicular to the fibre direction (Figures 2 (a) and 2(b), resp.). When the compressive test was conducted perpendicular to the fibre direction, the load was applied perpendicular to the casting surface.

\subsubsection{Failure Pattern}

(1) During the test, upon failure of the ordinary concrete specimen (Figure 3), the concrete specimen's side surface perpendicular to the loading surface broke and collapsed to the ground. A "bang" noise was heard when it failed. The concrete's load-bearing capacity rapidly dropped to zero. Cracks propagated through 


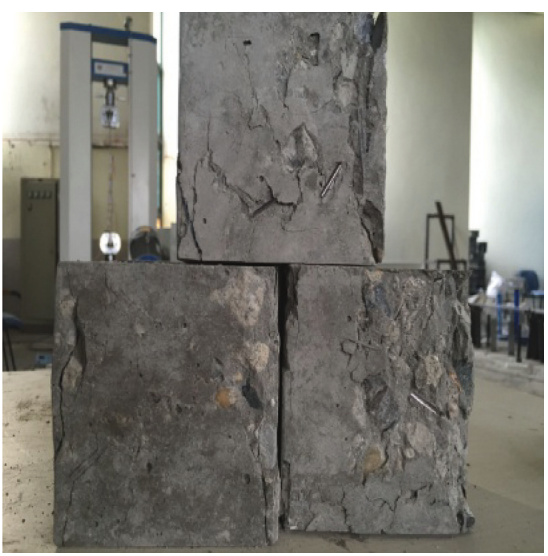

(a)

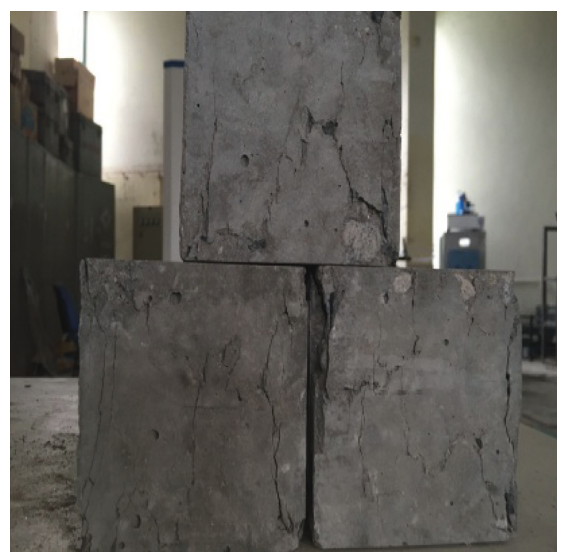

(b)

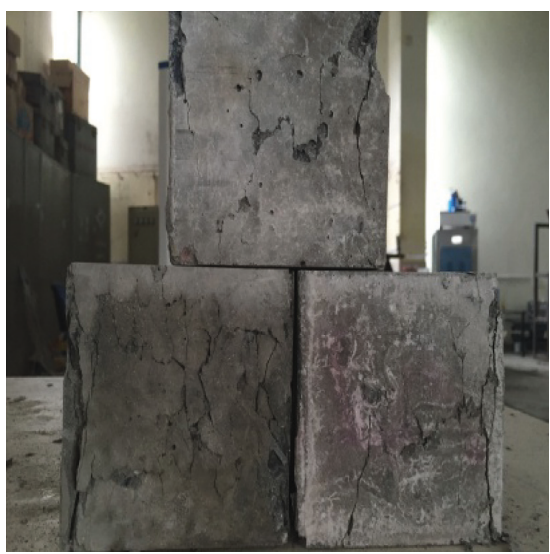

(c)

FIGURE 4: Failure patterns of cubic specimens of randomly distributed SFRC under compression. (a) $0.4 \%$; (b) $0.8 \%$; (c) $1.5 \%$.

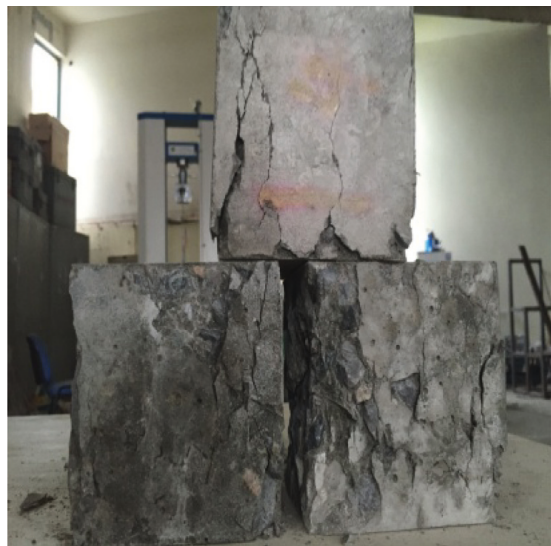

(a)

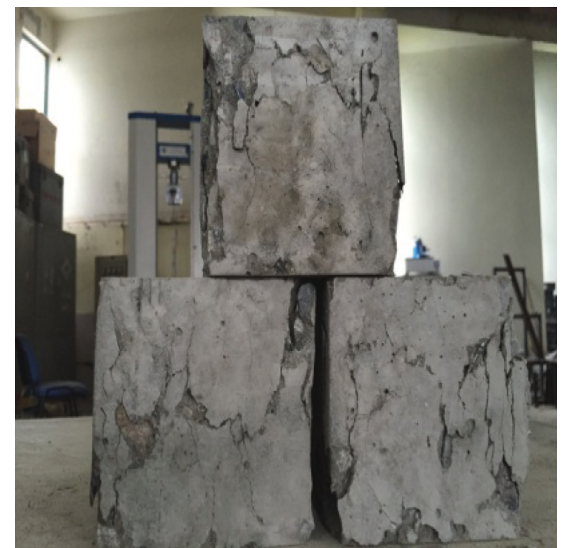

(b)

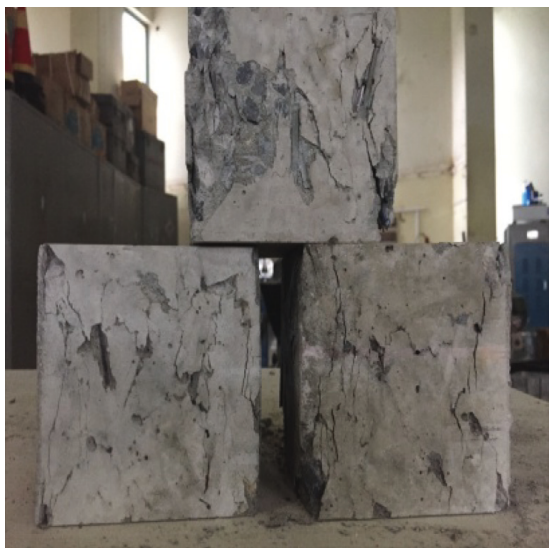

(c)

FIGURE 5: Failure patterns of cubic specimens of directionally distributed SFRC under (parallel) compressive loading. (a) $0.4 \%$; (b) $0.8 \%$; (c) 1.5\%.

the specimens along several paths, and the specimens failed suddenly.

(2) In the ordinary randomly distributed SFRC specimen (Figure 4), small cracks first appeared on the surface. As the load increased, cracks propagated along many paths but were not connected. The concrete surface was damaged, but the specimen's integrity was maintained. The specimens cracked but did not fail. As the load continued to increase until the specimen failed, the specimen showed obvious signs of failure.

When the fibre volume fraction was low (0.4\%), a small amount of concrete peeled from the specimen's surface. The damage pattern was similar to that observed in the ordinary concrete specimens but was not identical. At higher fibre volume fractions $(0.8 \%$ and $1.5 \%)$, the specimens maintained good integrity under compression; only a few discontinuous cracks formed on the specimens' surfaces.

(3) In the failure tests on directionally distributed SFRC specimens under compressive loading, the load can be applied either parallel or perpendicular to the fibre direction.
When the compressive load was applied parallel to the fibre direction (Figures 5 and 6), in specimens with a low fibre volume fraction $(0.4 \%)$, the failure pattern was similar to that of ordinary concrete, and the concrete in the specimen collapsed at a large area of the surfaces. Cracks propagated from the top to the bottom of the specimen. As the fibre volume fraction increased (to $0.8 \%$ ), the failure pattern changed. The surface integrity increased, and no through-going cracks formed. As the fibre volume fraction continued to increase $(1.5 \%-1.8 \%)$, small-scale areas on the specimens' surfaces started to collapse, and large cracks formed, which compromised the overall integrity.

When the compressive load was applied perpendicular to the fibre direction (Figure 7), in the specimen with a low fibre volume fraction $(0.4 \%)$, a small amount of concrete collapsed from the specimen's surface, and many nonthrough-going cracks formed. As the fibre volume fraction increased (to $0.8 \%$ and $1.5 \%$ ), the specimen failure pattern continued to change until no concrete collapsed from the surface, and only nonthrough-going cracks formed. Crack propagation was hindered, and the specimens maintained good integrity. 


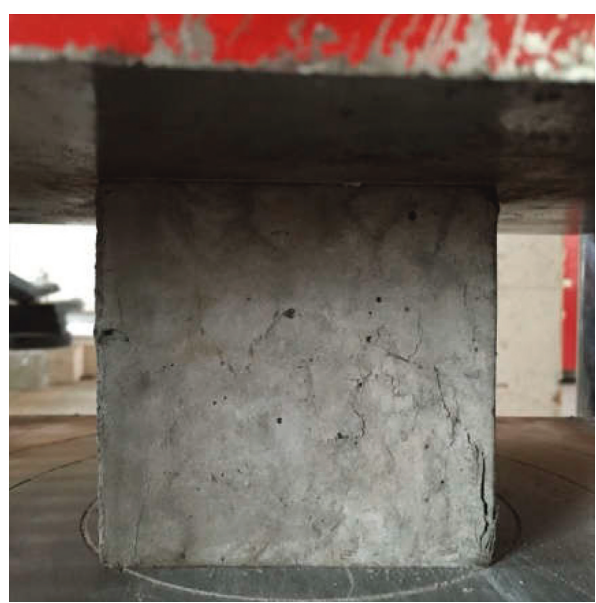

(a)

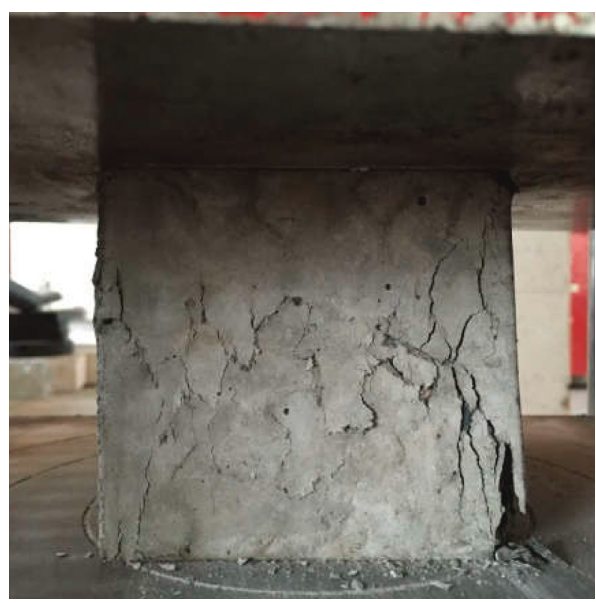

(c)

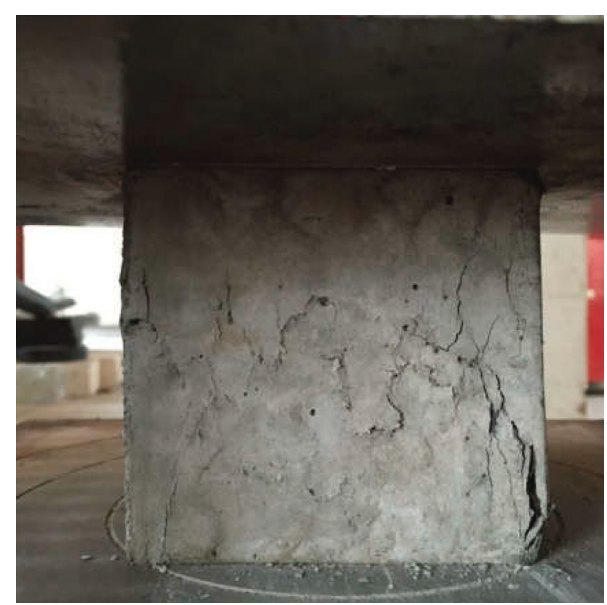

(b)

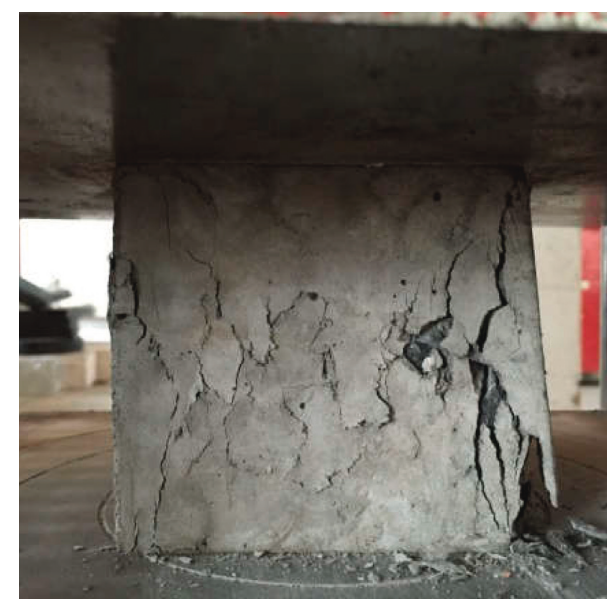

(d)

FIGURE 6: Failure process of a cubic specimen of directionally distributed SFRC under (parallel) compressive loading.

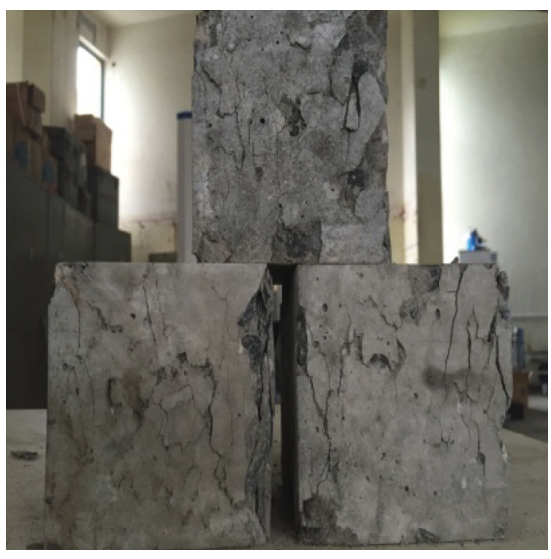

(a)

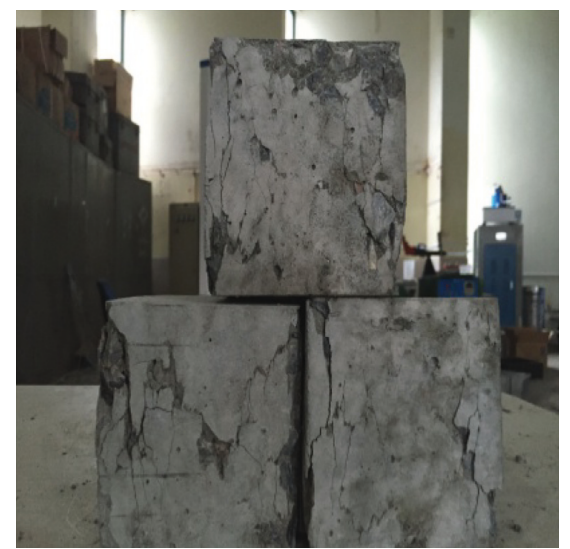

(b)

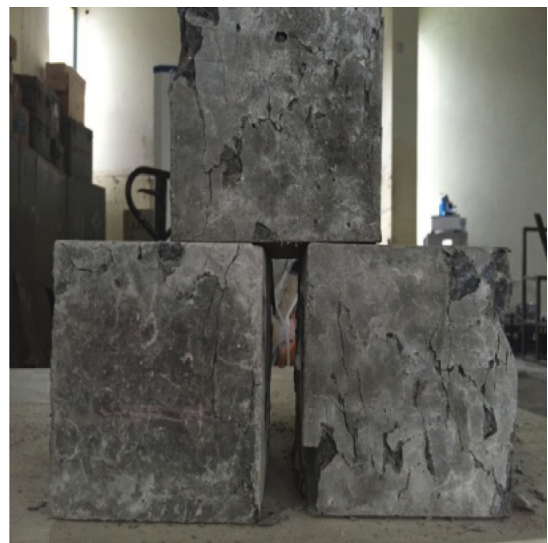

(c)

FIGURE 7: Failure pattern of a cubic specimen of directionally distributed SFRC under (perpendicular) compressive loading. (a) 0.4\%; (b) $0.8 \%$; (c) $1.5 \%$.

3.1.2. Test Results. The compressive test results are shown in Table 3 and Figure 8, in which benchmark concrete represents the ordinary concrete specimen, "Random steel fibre-reinforced concrete" represents the ordinary randomly distributed SFRC specimen, "Directional SFRC" represents the directionally distributed SFRC specimen, and $V_{\mathrm{f}}$ is the volume fraction of steel fibres in the concrete specimen. When $V_{\mathrm{f}}=1.0 \%$, the converted 
TABLE 3: Compressive strength of cubic specimens.

\begin{tabular}{lccc}
\hline Specimen number & $\begin{array}{c}V_{\mathrm{f}} \\
(\%)\end{array}$ & $\begin{array}{c}\text { Compressive } \\
\text { strength of cubic } \\
\text { specimens (MPa) }\end{array}$ & $\begin{array}{c}\text { Comparison } \\
\text { with benchmark } \\
\text { concrete }\end{array}$ \\
\hline Benchmark concrete & 0.0 & 49.2 & 1.00 \\
& 0.4 & 48.7 & 0.99 \\
& 0.6 & 52.2 & 1.06 \\
Random SFRC & 0.8 & 51.7 & 1.05 \\
& 1.0 & 52.9 & 1.08 \\
& 1.2 & 54.8 & 1.12 \\
& 1.5 & 56.8 & 1.16 \\
Directional SFRC & 0.8 & 51.0 & 1.24 \\
(parallel) & 1.8 & 57.3 & 1.17 \\
& 0.4 & 57.3 & 1.20 \\
& 0.6 & 58.9 & 1.13 \\
& 1.2 & 52.9 & 1.10 \\
& 1.5 & 54.9 & 1.08 \\
& 1.8 & 54.3 & 1.12 \\
Directional SFRC & 0.4 & 59.5 & 1.11 \\
(perpendicular) & 0.8 & 55.8 & 1.21 \\
& 1.0 & 54.7 & 1.22 \\
& 1.2 & 57.0 & 1.14 \\
& 1.5 & 60.7 & 1.16 \\
& 1.8 & 56.7 & 1.24 \\
& & & 1.15 \\
\hline
\end{tabular}

weight content of the steel fibres embedded in the SFRC is $80 \mathrm{~kg} / \mathrm{m}^{3}$.

Table 3 and Figure 8 show the following:

(1) When the fibre volume fraction is below $1.8 \%$, the compressive strength of the ordinary randomly distributed SFRC specimens increases with increasing fibre volume fraction. The maximum strength occurs when the volume fraction is $1.8 \%$ and is $24 \%$ higher than that of ordinary concrete.

(2) In the directionally distributed SFRC specimens, the compressive strength is higher even when the fibre volume fraction is low $(0.6 \%)$ (compared with the compressive strength of ordinary concrete, the compressive strengths in the two loading directions are $20 \%$ higher (parallel) and 22\% higher (perpendicular)). As the fibre volume fraction increases, the compressive strength begins to decrease. When compression is applied parallel to the fibre direction, the compressive strength is lowest when the fibre volume fraction is $1.2 \%$ and is lower than that of the ordinary randomly distributed SFRC. The strength increases slightly as the fibre volume fraction increases, but it is always lower than that of the ordinary randomly distributed SFRC. When the compression is applied perpendicular to the fibre direction, the compressive strength is the lowest when the fibre volume fraction is $1.0 \%$, and it increases gradually as the fibre ratio increases. When the fibre volume fraction is $1.5 \%$, the compressive strength of the SFRC reaches its maximum (24\% higher than that of ordinary concrete). However,

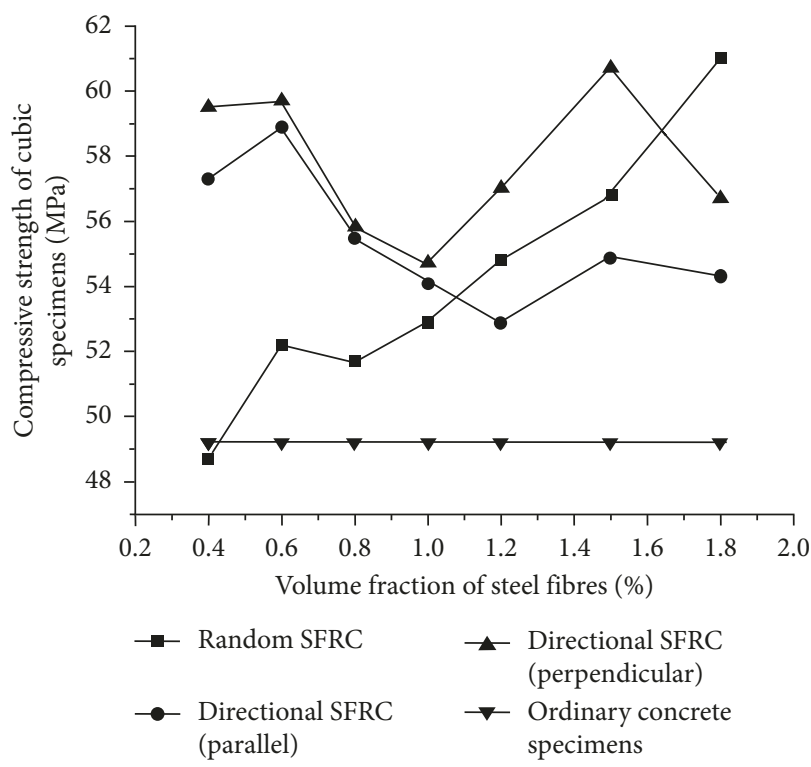

FIGURE 8: Compressive strengths of cubic specimens with different fibre contents.

further increases in the steel fibre ratio result in a sharp decrease in strength.

(3) In the directionally distributed SFRC specimens, the compressive strengths of specimens under compression in the two directions (parallel and perpendicular to the fibre direction) are not significantly different when the fibre volume fraction is low (less than 1\%). As the fibre volume fraction increases $(1.2 \%-1.8 \%)$, the anisotropy of the specimens increases gradually.

\subsubsection{Effect of the Fibre Volume Fraction and Direction on the Compressive Strength of Specimens}

(1) Effect of the Fibre Volume Fraction on the Compressive Strength. A comparison of the test results discussed above shows that as the fibre volume fraction increases, the compressive strengths of cubic specimens of both ordinary randomly distributed SFRC and directionally distributed SFRC increase. However, a higher fibre volume fraction does not necessarily result in a greater increase in the compressive strength; the compressive strengths of some specimens with high fibre volume fractions are significantly lower. A possible reason is that as more fibres are incorporated into the concrete, the fibres' specific surface area increases; thus, some fibres are not adequately coated by the concrete slurry, and the spaces between the fibres are not completely filled by the concrete slurry. Therefore, the compactness of the fibrereinforced concrete decreases. In addition, the increased usage of fibres hinders the casting of the specimens. The specimens are not uniformly vibration solidified, so the fibres are unevenly distributed in the specimens [23-26].

The tests in this study clearly show that, in both ordinary randomly distributed SFRC and directionally distributed SFRC specimens, when the fibre volume fraction is approximately $0.8-1.0 \%$, the compressive strength of the 
TABLE 4: Elastic modulus of concrete.

\begin{tabular}{lccc}
\hline Specimen number & $V_{\mathrm{f}}(\%)$ & Elastic modulus (MPa) & Compared with benchmark concrete \\
\hline Benchmark concrete & 0.0 & 41,400 & 1.00 \\
Random SFRC & 0.8 & 43,200 & 1.04 \\
& 1.6 & 43,500 & 1.05 \\
Directional SFRC & 0.8 & 45,700 & 1.10 \\
& 1.6 & 57,600 & 1.39 \\
\hline
\end{tabular}

specimens is significantly lower. This phenomenon is most likely caused by the characteristics of the milled steel fibres used in this experiment. The same result was found in other studies $[27,28]$. These findings demonstrate that for this kind of milled steel fibre, which has a special shape, the fibre volume faction features an optimum range. Within this range, the steel fibres have the best reinforcement effect on the concrete's compressive strength. For both ordinary randomly distributed SFRC and directionally distributed SFRC, fibre volume fractions of $0.8 \%$ to $1.0 \%$ should be avoided.

(2) Effect of the Fibre Direction on the Compressive Strength. A comparison of the compressive strengths of ordinary randomly distributed SFRC with those of the directionally distributed SFRC specimens with same fibre volume fraction under compression in two directions shows that when the fibre volume fraction is low, the strength of the directional SFRC in both loading directions is much higher than that of ordinary random SFRC. As the fibre volume fraction increases, the compressive strength of directional SFRC shows clear anisotropy in the two loading directions. When the compression is applied parallel to the fibre direction, the compressive strength is lower than that of ordinary random SFRC; in contrast, when compression is applied perpendicular to the fibre direction, the compressive strength is higher than that of ordinary random SFRC.

Further analysis shows that when the fibre volume fraction is high and the compression is applied perpendicular to the fibre direction, as the loading increases, the transverse deformation of the specimen is constrained by the fibres. The stress state in the specimen is similar to multiaxial compression. Therefore, its compressive strength is much higher than that of the ordinary concrete and random SFRC specimens. When the compression is applied parallel to the fibre direction, the fibres cannot effectively constrain the transverse deformation of the specimens. When the fibre volume fraction is high, the compactness of the concrete is reduced; thus, the compressive strength decreases as the fibre volume fraction increases.

3.2. Static Compression Test of the Elastic Modulus. The elastic modulus is an important mechanical property of concrete that reflects the relationship between the stress and the strain in the concrete. This parameter is necessary for calculating the deformation of the concrete structure, crack development, and thermal stress in concrete. There are three ways to calculate the elastic modulus: (1) the tangent modulus, (2) the secant modulus, and (3) the chord modulus. The static compressive elastic modulus studied in this experiment is actually the concrete's chord modulus.

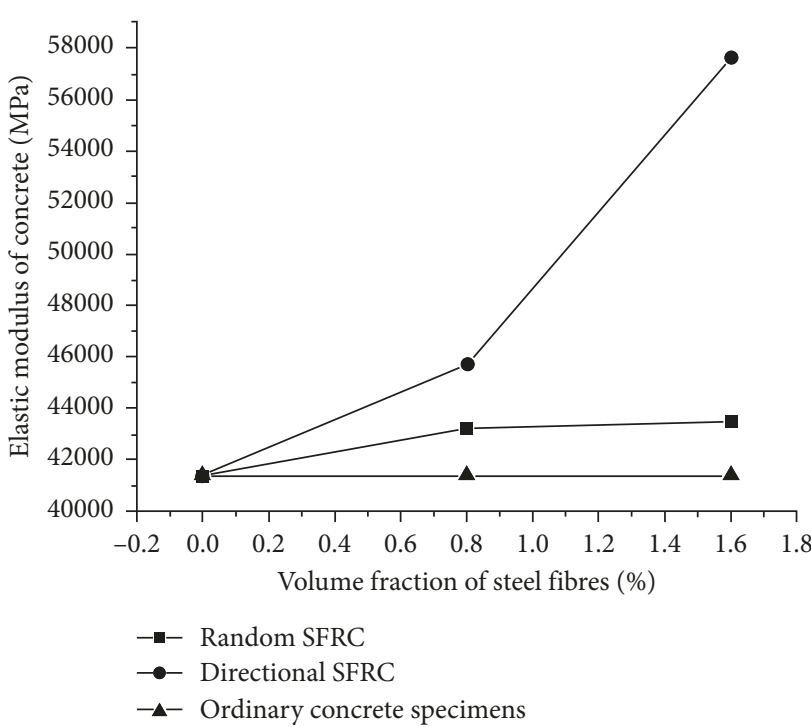

FIgURE 9: Elastic modulus of concrete with different fibre volume fractions.

In accordance with the Chinese "Standard test method for mechanical properties of ordinary concrete" (GB/T 50081-2002), a prism with the dimensions of $150 \mathrm{~mm} \times 150 \mathrm{~mm} \times 150 \mathrm{~mm}$ was used as the standard specimen. Six specimens were made for each test. Of the six specimens, three were used to measure the axial compressive strength, and the other three were used to measure the elastic modulus of the concrete.

Static compressive elastic modulus tests were conducted with ordinary concrete specimens, randomly distributed SFRC specimens with two fibre volume fractions $\left(V_{\mathrm{f}}\right.$ values of $0.8 \%$ and $1.6 \%$ ), and directionally distributed SFRC specimens with two fibre volume fractions $\left(V_{\mathrm{f}}\right.$ values of $0.8 \%$ and $1.6 \%)$. In the directional SFRC, the fibres were oriented in the longitudinal direction of the specimen.

3.2.1. Test Results. Table 4 and Figure 9 show the results for the static compressive elastic modulus, in which benchmark concrete represents the ordinary concrete specimen, "Random SFRC" represents the ordinary randomly distributed SFRC specimen, "Directional SFRC" represents the directionally distributed SFRC specimen, and $V_{\mathrm{f}}$ is the volume fraction of steel fibres in the concrete specimens. When $V_{\mathrm{f}}=1.0 \%$, the converted weight content of the steel fibres embedded in the SFRC is $80 \mathrm{~kg} / \mathrm{m}^{3}$.

Table 4 and Figure 9 show the following:

(1) The elastic modulus of the ordinary randomly distributed SFRC is higher than that of the ordinary 
TABLE 5: Comparison of the elastic moduli of ordinary randomly distributed SFRC (unit: MPa).

\begin{tabular}{|c|c|c|c|c|c|}
\hline $\begin{array}{l}\text { Steel fibre volume } \\
\text { fraction (\%) used in } \\
\text { different theories and } \\
\text { formulas }\end{array}$ & $\begin{array}{c}\text { Results given by } \\
\text { composite materials } \\
\text { theory }\end{array}$ & $\begin{array}{l}\text { Results given by the } \\
\text { empirical formula } \\
\text { proposed by Yuan et al. }\end{array}$ & $\begin{array}{l}\text { Results given by the } \\
\text { empirical formula } \\
\text { proposed by Gao et al. }\end{array}$ & $\begin{array}{l}\text { Results given by the } \\
\text { empirical formula } \\
\text { proposed by Wang } \\
\text { et al. }\end{array}$ & $\begin{array}{c}\text { Experimental } \\
\text { values }\end{array}$ \\
\hline 0.8 & 41,400 & \multirow{2}{*}{37,200} & 44,100 & 40,800 & 43,200 \\
\hline 1.6 & 41,500 & & 44,400 & 45,600 & 43,500 \\
\hline
\end{tabular}

TABle 6: Comparison of the elastic moduli of directionally distributed SFRC (unit: MPa).

\begin{tabular}{lccc}
\hline $\begin{array}{l}\text { Steel fibre volume fraction (\%) used in } \\
\text { different theories and formulas }\end{array}$ & $\begin{array}{c}\text { Results given by composite } \\
\text { materials theory }\end{array}$ & $\begin{array}{c}\text { Results given by semiempirical formulas } \\
\text { proposed by Balpin-Tsal }\end{array}$ & $\begin{array}{c}\text { Experimental } \\
\text { values }\end{array}$ \\
\hline 0.8 & 41,800 & 42,000 & 45,700 \\
1.6 & 42,200 & 42,600 & 57,600 \\
\hline
\end{tabular}

concrete, but it is only slightly higher. At the maximum fibre volume fraction of $1.6 \%$, the elastic modulus is only $5 \%$ higher.

(2) Compared with the ordinary concrete, the elastic modulus of the directionally distributed SFRC increases significantly as the fibre volume fraction increases. When the fibre volume fraction is $0.8 \%$, the elastic modulus of the directionally distributed SFRC is $10 \%$ higher than that of the ordinary concrete. As the fibre volume fraction increases to $1.6 \%$, the elastic modulus increases by $39 \%$ compared with that of the ordinary concrete. The elastic modulus of directional SFRC clearly increases significantly as the fibre volume fraction increases.

3.2.2. Comparison with the Results from Other Studies. Based on experiments, many scholars have established empirical or semiempirical formulas to evaluate the elastic modulus of ordinary SFRC. However, because of differences in the concrete mixture, the material properties of the concrete (e.g., the aggregates' elastic modulus, composition, and variety), the amount used, the test methods, and the results of these formulas vary widely. In this study, several representative formulas [29-32] were selected, and the test results were compared with the values produced by these formulas.

(1) Elastic Modulus of Directionally Distributed SFRC. BalpinTsal proposed the following semi-empirical formulas [32]:

$$
\begin{aligned}
& E=\frac{1+2 \gamma V_{\mathrm{f}}}{1-\gamma V_{\mathrm{f}}} E_{\mathrm{c}}, \\
& \gamma=\frac{\left(E_{\mathrm{f}} / E_{\mathrm{c}}\right)-1}{\left(E_{\mathrm{f}} / E_{\mathrm{c}}\right)+2},
\end{aligned}
$$

where $E$ is the elastic modulus of the SFRC $(\mathrm{MPa}), V_{\mathrm{f}}$ is the volume fraction of steel fibres (\%), $E_{\mathrm{c}}$ is the elastic modulus of ordinary concrete $(\mathrm{MPa})$, and $E_{\mathrm{f}}$ is the elastic modulus of steel fibres $(\mathrm{MPa})$.

(2) The Elastic Modulus of Ordinary Three-Dimensional Randomly Distributed SFRC. Based on experiments, Yuan et al. proposed the following empirical formula [29]:

$$
Y=35.814+0.0306 X_{1}+0.0034 X_{2} \text {, }
$$

where $Y$ is the elastic modulus of SFRC $(\mathrm{GPa}), X_{1}$ is the length to diameter ratio of the steel fibres, and $X_{2}$ is the tensile strength of the steel fibres (GPa).

Based on experiments, Gao et al. proposed the following empirical formula [31]:

$$
E=34800 f_{\mathrm{cu}}^{0.06}
$$

where $E$ is the elastic modulus of the SFRC $(\mathrm{MPa})$ and $f_{\mathrm{cu}}$ is the compressive strength of the SFRC (MPa).

Based on experiments, Wang et al. proposed the following empirical formula [30]:

$$
y=26600 x^{2}-37.4 x+39.372,
$$

where $x$ is the steel fibre volume fraction (\%) and $y$ is the elastic modulus of the SFRC (GPa).

The SFRC elastic modulus values produced by the formula based on the theory of composite materials [27, 28, 33-35] and by the semiempirical and empirical formulas in the studies discussed above were compared with the test results in this study. The results are listed in Tables 5 and 6 .

A comparison of the results in Tables 5 and 6 shows the following:

(1) There are differences among the elastic moduli of randomly distributed SFRC given by the theory of composite materials, the empirical formulas [36, 37], and the experimental values. The results given by the empirical formula proposed by Yuan et al. differ the most from the theoretical values (up to $14.5 \%$ ). The differences among the results given by the other formulas and theoretical values and the experimental values are all approximately 5\%. Therefore, the results given by these formulas and the theory of composite materials can be used as a general reference.

(2) The elastic moduli of the directionally distributed SFRC given by the theory of composite materials and the semiempirical formulas all differ from the experimental values. Therefore, the determination of the elastic modulus of directionally distributed SFRC is more complicated than that of ordinary randomly distributed SFRC. The existing theoretical and 
semiempirical formulas do not completely satisfy the engineering demands. Consequently, additional studies should be conducted in this area.

\section{Conclusions}

(1) The properties of directionally distributed SFRC specimens under compression show no obvious anisotropy when the fibre volume fraction is low. When compression is applied perpendicular to the fibre direction, the damage on the specimen's surface when the specimen fails is limited; only small cracks form on the specimen's surface, and the integrity of the specimen is maintained.

(2) When compression is applied parallel to the fibre direction and the fibre volume fraction is high, the specimen's failure pattern resembles that of ordinary concrete. The compressive strength of ordinary randomly distributed SFRC increases steadily as the fibre volume fraction increases. Its strength is between the compression of parallel and perpendicular fibre directions.

(3) The elastic modulus of ordinary randomly distributed SFRC is not affected significantly by changes in the steel fibre volume fraction. However, the elastic modulus of the directionally distributed SFRC specimen is greatly affected by changes in the steel fibre volume fraction. When the fibre volume fraction was $1.6 \%$, the elastic modulus was $39 \%$ higher than that of ordinary concrete. It must be quantified as an engineering parameter through experimental studies.

(4) The specimen's elastic modulus of directionally distributed SFRC increased significantly. The main reason is that although the fibre volume fraction is low, as in ordinary randomly distributed SFRC, the fibres' directional distribution may change the elastic deformation properties of the concrete matrix. This change increases the vertical stiffness of the concrete prism in the test, which increases the elastic modulus of the specimen.

(5) The results for directionally distributed SFRC given by existing semiempirical formulas and theoretical calculations are different from the experimental values. The determination of the elastic modulus of directionally distributed SFRC is more complex than that of ordinary randomly distributed SFRC. Therefore, further research in this area is needed for the formulas.

\section{Data Availability}

The data used to support the findings of this study are available from the corresponding author upon request.

\section{Conflicts of Interest}

The authors declare that there are no conflicts of interest regarding the publication of this paper.

\section{Acknowledgments}

This research was supported by the National Basic Research Program of China (973 Program) under Grant no. 2013CB036303 and the Zhejiang Provincial Public Interest Technology Research Industrial Project under Grant no. 2016C31099.

\section{References}

[1] B. Gangil, A. Patnaik, A. Kumar, and M. Kumar, "Investigations on mechanical and sliding wear behaviour of short fibre-reinforced vinylester-based homogenous and their functionally graded composites," Proceedings of the Institution of Mechanical Engineers Part L-Journal of Materials-Design and Applications, vol. 226, no. 4, pp. 300-315, 2012.

[2] J. P. Romualdi and G. B. Batson, "Mechanics of crack arrest in concrete," Journal of Engineering Mechanics Division, vol. 89, no. 3, pp. 147-168, 1963.

[3] A. E. Naaman, F. Moavenzadeh, and F. J. Mcgarry, "Probabilistic analysis of fibre reinforced concrete," Journal of the Engineering Mechanics Division, vol. 100, no. 2, pp. 397-413, 1974.

[4] G. Zhao and C. Huang, Summary of Research on Strengthening Mechanism of Steel Fiber Reinforced High-Strength Concrete and Design Method, Structure Laboratory of Department of Civil Engineering, Dalian University of Technology, Dalian, China, 1993.

[5] J. P. Romualdi and J. A. Mandel, "Tensile strength of concrete affected by uniformly distributed closely spaced short lengths of wire reinforcements," Journal of the American Concrete Institute, vol. 61, pp. 657-671, 1964.

[6] J. Zhao and L. Cheng, Design and Construction of Steel Fiber Reinforced Concrete, Heilongjiang Science and Technology Press, Harbin, China, 1988.

[7] S. M. Abtahi, M. Sheikhzadeh, and S. M. Hejazi, "Fiberreinforced asphalt-concrete-a review," Construction and Building Materials, vol. 24, no. 6, pp. 871-877, 2010.

[8] J. Schnell, K. Schladitz, and F. Schuler, "Direction analysis of fibres in concrete on basis of computed tomography," Betonund Stahlbetonbau, vol. 105, no. 2, pp. 72-77, 2010.

[9] A. Patnaik, C. MacDonald, M. MacDonald, and V. Ramakrishnan, "Review of ASTM C1399 test for the determination of average residual strength of fiber reinforced concrete," in Proceedings of the First International Conference on Recent Advances in Concrete Technology, pp. 687-696, Washington, DC, USA, September 2007.

[10] X. B. Lu and C. T. T. Hsu, "Behavior of high strength concrete with and without steel fiber reinforcement in triaxial compression," Cement and Concrete Research, vol. 36, no. 9, pp. 1679-1685, 2006.

[11] T. Fukushima, "Resources circulation-oriented ecomaterials design of continuous fiber reinforced concrete (FRPRC)," in Proceedings of the International Conference on Processing \& Manufacturing of Advanced Materials (Thermec'2003) Pts 1-5, vol. 426-432, pp. 3323-3328, Madrid, Spain, July 2003.

[12] A. Poitou, F. Chinesta, and G. Bernier, "Orienting fibers by extrusion in reinforced reactive powder concrete," Journal of Engineering Mechanics, vol. 127, no. 6, pp. 593-598, 2001.

[13] R. Mu, "Analysis of the distribution of steel fiber in aligned steel fiber reinforced concrete using digital X-ray CT scanning," Journal of Chinese Electron Microscopy Society, no. 6, pp. 487-491, 2015.

[14] T. Ponikiewski and J. Katzer, "X-ray computed tomography of fibre reinforced self-compacting concrete as a tool of assessing 
its flexural behaviour," Materials and Structures, vol. 49, no. 6, pp. 2131-2140, 2016.

[15] Ministry of Housing and Urban-Rural Development of the People's Republic of China, Standard for Test Method of Performance on Ordinary Fresh Concrete, China Architecture and Building Press, Beijing, China, 2016.

[16] H. Li, Investigation on the Preparation and Properties of the Aligned Steel Fiber Reinforced Concrete, Hebei University of Technology, Tianjin, China, 2013.

[17] A. Najigivi, A. Nazerigivi, and H. R. Nejati, "Contribution of steel fiber as reinforcement to the properties of cement-based concrete: a review," Computers and Concrete, vol. 20, no. 2, pp. 155-164, 2017.

[18] T. Ponikiewski and J. Katzer, "Mechanical properties and fibre density of steel fibre reinforced self-compacting concrete slabs by DIA and XCT approaches," Journal of Civil Engineering and Management, vol. 23, no. 5, pp. 604-612, 2017.

[19] A. Jansson, I. Lofgren, K. Lundgren, and K. Gylltoft, "Bond of reinforcement in self-compacting steel-fibre-reinforced concrete," Magazine of Concrete Research, vol. 64, no. 7, pp. 617-630, 2012.

[20] L. Soufeiani, S. N. Raman, M. Z. B. Jumaat, U. J. Alengaram, G. Ghadyani, and P. Mendis, "Influences of the volume fraction and shape of steel fibers on fiber-reinforced concrete subjected to dynamic loading-a review," Engineering Structures, vol. 124, pp. 405-417, 2016.

[21] B. Nepal, C. S. Chin, and S. Jones, "A review on agricultural fibre reinforced concrete," in Sustainable Buildings and Structures, pp. 125-130, Taylor \& Francis Group, London, UK, 2016.

[22] Ministry of Housing and Urban-Rural Development of the People's Republic of China, Steel Fiber Reinforced Concrete, Standards Press of China, Beijing, China, 2015.

[23] D. Daviau-Desnoyers, J. P. Charron, B. Massicotte, P. Rossi, and J. L. Tailhan, "Influence of reinforcement type on macrocrack propagation under sustained loading in steel fibre-reinforced concrete," Structural Concrete, vol. 17, no. 5, pp. 736-746, 2016.

[24] H. Ahmad, M. H. M. Hashim, S. H. Hamzah, and A. Abu Bakar, "Steel fibre reinforced self-compacting concrete (SFRSC) performance in slab application: a review," in Proceeedings of the International Conference on Advanced Science, Engineering and Technology (ICASET 2015), p. 1774, Penang, Malaysia, December 2015

[25] S. Abdallah, M. Z. Fan, X. M. Zhou, and S. Le Geyt, "Anchorage effects of various steel fibre architectures for concrete reinforcement," International Journal of Concrete Structures and Materials, vol. 10, no. 3, pp. 325-335, 2016.

[26] S. Mukhopadhyay and S. Khatana, "A review on the use of fibers in reinforced cementitious concrete," Journal of Industrial Textiles, vol. 45, no. 2, pp. 239-264, 2015.

[27] R. Mu, Q. M. Zhao, and W. Q. Tian, "Investigation on the preparation and properties of aligned steel fibre reinforce cement paste," Journal of Hebei University of Technology, no. 2, pp. 101-104, 2012.

[28] F. Y. Li, "A concrete modeling structure with directional steel fibres," China Patent 201621193064.9, 2017.

[29] H. Wang, Steel Fiber Reinforced Concrete, China Water and Power Press, Beijing, China, 1985.

[30] R. Wang, Mechanical Experiment Research on Steel Fiber Reinforced Concrete and Numerical Simulation of Failure Process, Northeastern University, Shenyang, China, 2004.

[31] D. Gao, J. Zhao, and J. Tang, "A experimental study on elastic modulus of fiber reinforced high-strength concrete," Industrial Construction, vol. 34, no. 10, pp. 47-49, 2004.
[32] Z. Zhang and F. Zhang, "Theoretical calculation of elastic modulus of steel fiber reinforced concrete," in Proceedings of the 4th National Academic Conference of Fiber Cement and Fiber Concrete, Nanjing, China, 1992.

[33] X. S. Lin, High and Ultra High Strength Concrete with Steel Fibres, Science Press, Beijing, China, 2002.

[34] S. C. Lee, J. Y. Cho, and F. J. Vecchio, "Tension-stiffening model for steel fiber-reinforced concrete containing conventional reinforcement," ACI Structural Journal, vol. 111, no. 3, pp. 717-718, 2014.

[35] Z. F. Jiang, "Steel fibre concrete," Architecture Technology, no. 1, pp. 56-59, 1986.

[36] M. Gencoglu, T. Uygunoglu, F. Demir, and K. Guler, "Prediction of elastic modulus of steel-fiber reinforced concrete (SFRC) using fuzzy logic," Computers and Concrete, vol. 9, no. 5, pp. 389-402, 2012.

[37] E. Shadafza and R. S. Jalali, "The elastic modulus of steel fiber reinforced concrete (SFRC) with random distribution of aggregate and fiber," Civil Engineering Infrastructures Journal, vol. 49 , no. 1 , pp. 21-32, 2016. 


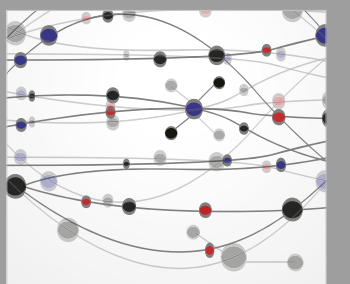

The Scientific World Journal
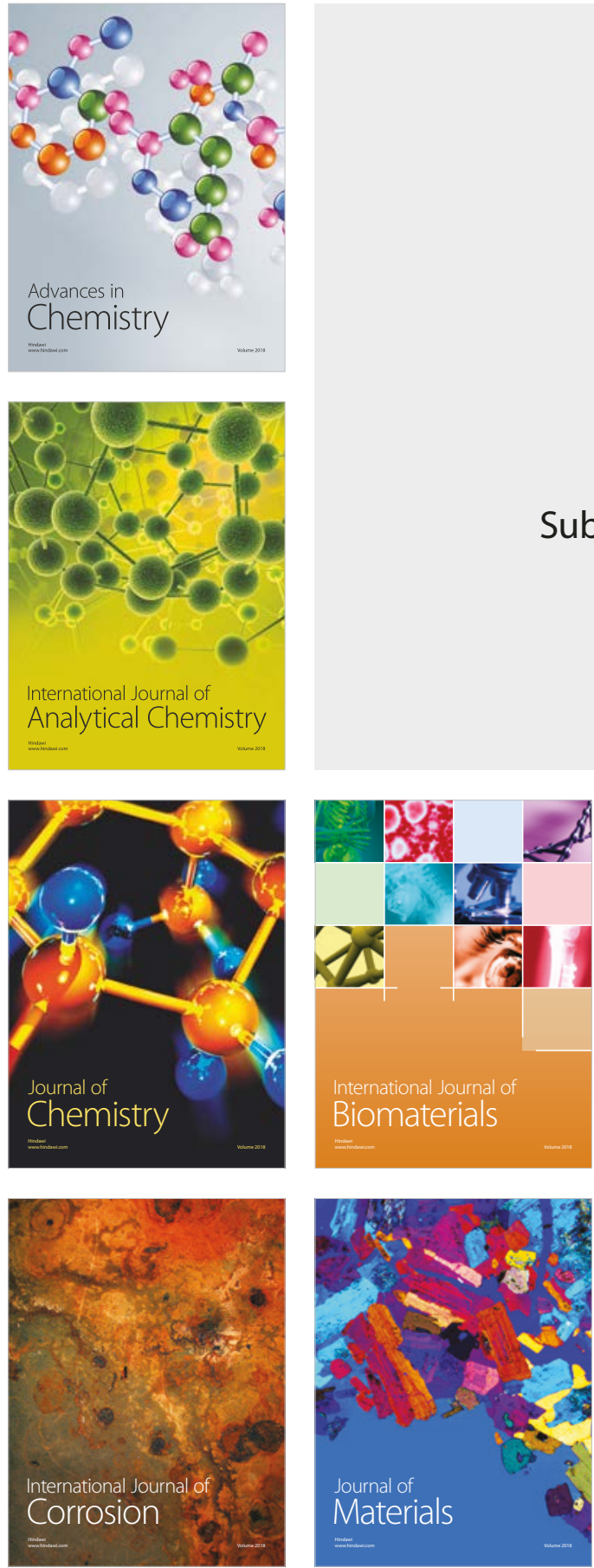

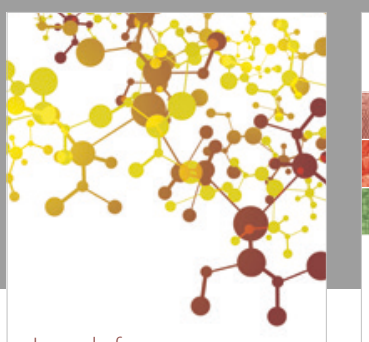

Journal of

Applied Chemistry
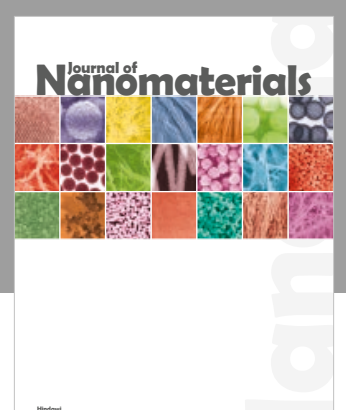

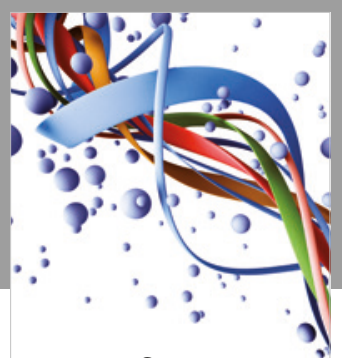

Scientifica

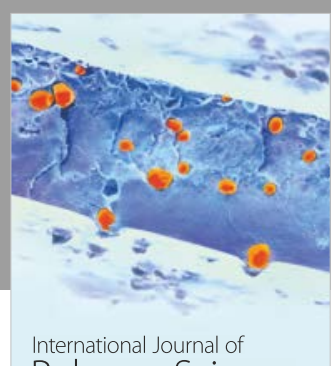

Polymer Science

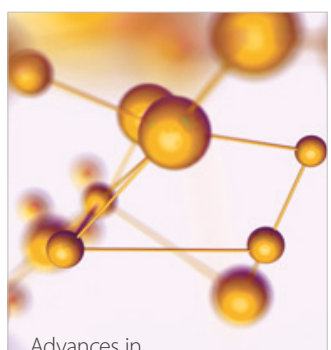

Physical Chemistry
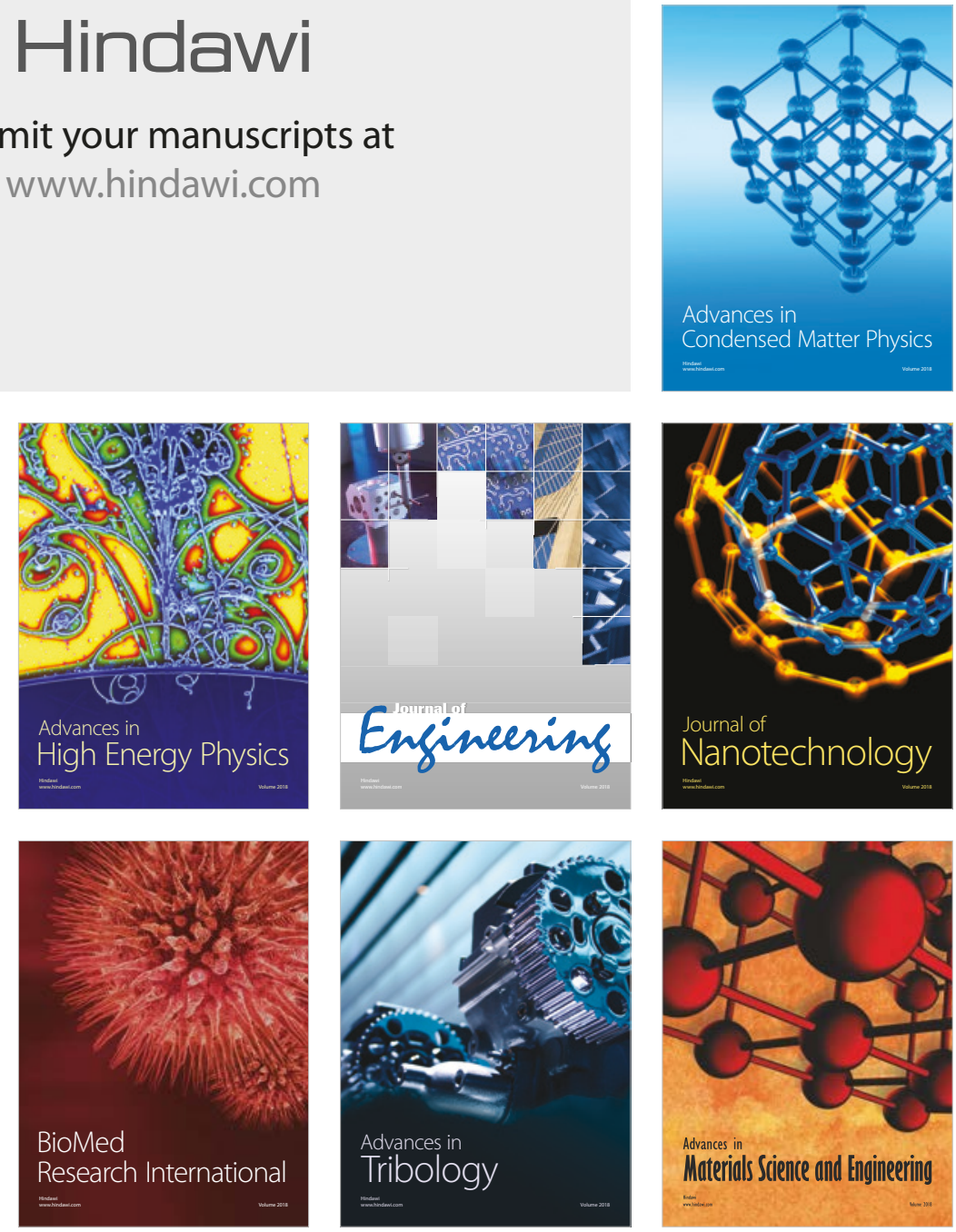